\title{
A tool to estimate indoor temperature in buildings with a risk of overheating in the temperate European climate zone
}

\author{
Dorota Bzowska, ${ }^{1, *}$ \\ ${ }^{1}$ Inst. of Civil Engine., Warsaw University of Technology, Łukasiewicza 17, 09-400 Plock, Poland
}

\begin{abstract}
A regression model is proposed, as a simple tool, for estimating indoor temperature in thermally insulated buildings, applicable to situations when only natural ventilation in midsummer is concerned. Knowledge of this temperature, at a primary stage of a design process, might help avoiding the risk of overheating during summertime. The proposed regression model is applicable for buildings located in the temperate European climate zone. To create the regression model, the values of indoor temperature are calculated for incrementally increasing thermal resistance of outside walls, and gradual enlargement of windows. The outside partitions were covered with an insulating material with a thickness of 3 to $30 \mathrm{~cm}$. For every insulation layer the window surface to wall surface ratio (wwr) was changing from $5 \%$ to $50 \%$. The wwr changes were applied to a selected window, facing east, south and west in turn while wwr for the remaining orientations was kept at a constant value $1 / 10$ of the wall. The considered building is representative for a single family house located at an open space. The algorithm of computations was based on the finite differences method, where feedback between the thermal model and the airflow model was applied.
\end{abstract}

\section{Introduction}

The buildings with envelope's that have high thermal resistance equipped with natural ventilation can create an overheating risk during hot weather periods, even in the European temperature climate. The overheating risk should be examined in all its aspects. As it is known, in the summer of 2003 a large number of deaths were reported in Paris. August of that year was extremely hot. However the temperature was not the only reason for so many deaths there. The main cause was a thermal environment created by air-tight buildings characterized by high thermal resistance of opaque elements and their lack of ability to accumulate intensive amounts of solar energy. Besides the sun, additional heat gains are created by numerous electronic devices the dwellings nowadays are equipped with. Natural ventilation simply cannot cope with such an amount of heat and these houses can be higher energy consumers during the summer season than heavy structures built of brick. Thermal comfort, especially with respect to avoiding overheating during hot periods of summer, should be of major interest during the design process $[2,19]$.

*Corresponding author: dor.bzowska@gmail.com 
When the heat transfer coefficient of a building's envelope was reduced and large south-oriented glazing surfaces were advanced, many architects are deeply convinced that this approach guarantees reduction of heat loads during winter time.

The effects of: windows' size and their orientation, types of glazing systems and coating, solar transmittance etc. on heating and cooling loads have been investigated for some years $[6-10,12,15]$. According to the research, monitoring and measurements, large windows do not have a major effect on the heating demand during winter time. The conclusion then is, that using large south-oriented together with east and west oriented windows in well insulated buildings may not improve energy performance for the whole year. Instead the risk of overheating during the hot summer may appear in these buildings unless they are equipped with some kinds of cooling system or hybrid ventilation. The concept of heat accumulation in massive elements of walls is very much worth considering as well.

Published sources propose quite a lot of concepts for eliminating overheating during extreme weather events in currently existing dwellings. Certain interventions are proposed to adapt existing dwellings to changed weather parameters. These numerous adaptations may involve for example: glazing systems, solar control, ventilation or thermal insulation, etc $[1,8-12,15,18]$. More advanced information on the behaviour of buildings in overheating situations can be found in the papers published by Coley and Kershaw, Porrit et al $[5,17]$. Energy performance and environment within a building mainly depend on the conditions assumed at the initial stage of the design [19]. The adequate choices made at the earliest stage of the design process should be aided by a simple calculation tool. Advanced simulations may not be used at this stage, as they would require a comprehensive set of input data, which is not available yet, as certain parameters are only finalized at the detailed engineering stage. Estimation of building's parameters such as indoor temperatures or ventilation air flows at the initial stage of the designing process, will allow adapting them to present weather parameters and changing climate. In the paper the regression model is proposed as a simple tool for estimating minimum and maximum temperature in buildings, where the surface of windows of the chosen orientation is being enlarged, while external walls are covered with an insulation layer 3 to $30 \mathrm{~cm}$ thick.

\section{The investigated building}

The investigated building is a model of a one-family dwelling designed as an open space structure. The building is equipped with a natural ventilation system and an internal heat accumulating mass. The building, which was originally constructed without any thermal insulation, used to be a highly typical object in the region. External walls were built of $38 \mathrm{~cm}$ thick bricks. At that time, resistance of building walls was $0.66 \mathrm{~m}^{2} \cdot \mathrm{K} / \mathrm{W}$, whereas the equivalent resistance of the roof was: $1.14 \mathrm{~m}^{2} \cdot \mathrm{K} / \mathrm{W}$. The resistance of the bottom floor, covered with parquetry, was $2.30 \mathrm{~m}^{2} \cdot \mathrm{K} / \mathrm{W}$. The value of overall heat transfer coefficient for this sort of building did not fit relevant standards even several years ago.

The overall internal dimensions of the building were $5 \times 5 \times 3 \mathrm{~m}$. The external walls faced south, north, west and east. Windows of $1.5 \mathrm{~m}^{2}$ and of heat transmittance coefficient $1.6 \mathrm{~W} /\left(\mathrm{m}^{2} \cdot \mathrm{K}\right)$ and transmitting coefficient is assumed to be 0.67 .

The windows were situated in southern, western, and eastern walls, each constituting 0.1 of the entire wall surface. The northern wall had no window.

The heat capacity of the envelope of the investigated building is: $4838 \mathrm{~kJ} / \mathrm{K}$ whereas for internal thermal mass is assumed to be $1134 \mathrm{~kJ} / \mathrm{K}$.

The procedure of covering the partitions with polystyrene foam was as follows: the first layer of the insulation had a thickness of $3 \mathrm{~cm}$, the second $-5 \mathrm{~cm}$, followed by more $5 \mathrm{~cm}$ layers up to the total insulation thickness of $30 \mathrm{~cm}$. Thermal resistance eventually reaches 
$7.8 \mathrm{~m}^{2} \cdot \mathrm{K} / \mathrm{W}$ at the insulation layer of $30 \mathrm{~cm}$, while for $15 \mathrm{~cm}$ it is $4.23 \mathrm{~m}^{2} \mathrm{~K} / \mathrm{W}$ and for $25 \mathrm{~cm}-6.60 \mathrm{~m}^{2} \mathrm{~K} / \mathrm{W} .3 \mathrm{~cm}$ and $5 \mathrm{~cm}$ layers of thermal insulation were taken into account, because inhabitants used to cover the external wall with such layers before the new regulations came into force. To investigate the influence of varying window-to-wall surface ratio on indoor temperature in a naturally ventilated residential building, a model for unsteady heat and air exchange processes was applied [3].

Heat, which influences the building during summertime and is included in calculations, comes from: solar energy and internal sources assumed at the level of $300 \mathrm{~W}$. That constant value of $300 \mathrm{~W}$ comes from occupants and equipment used inside.

As for the air exchange model, it was assumed in the calculation that the calibrated ventilation openings used during hot weather were situated on opposite walls. The dwelling is equipped with the ventilation air intake located in the north-oriented external wall, $1 \mathrm{~m}$ above the ground. Northern wind blowing into the intake is assumed to be assisting wind. The ventilation exhaust is situated at the top of south-oriented external wall. When the southern wind blowing into the exhaust is assumed to be opposing wind because reduces ventilating air flowing from the north intake towards the south-exhaust ventilating opening. It is assumed that the ventilation openings are very narrow to keep the pressure drops across them constant [14].

\section{The model of the unsteady heat and air exchange processes in buildings}

\subsection{Energy balance equation}

Heat is exchanged between the building and its surrounding by conduction, convection and radiation. Air ventilation is exchanged between the building and its surrounding too. The relations between these examined processes are expressed by the global enthalpy balance of a room and total air mass flow rate inflowing from the outside through a ventilation opening. The equation for flow rate is given according to Li \& Delsante [13].

It is assumed that the sources of heat that are examined in a naturally ventilated building are uniformly distributed over the whole area of the floor. These sources generate many convectional streams causing mixing of the air in the object [14]. The heat from solar radiation which is transferred through walls and windows into the space sums up with the internal heat sources and increases thermal buoyancy as well as heat accumulation in building partitions [14].

The natural air flow processes are driven by wind and a difference of air density resulting from different temperatures outside and inside the building. The wind can be either assisting or opposing. The difference between the external and internal air density is replaced by the difference of temperatures according to the Boussinesque approximation $\Delta \rho / \rho=\Delta T / T$ [14]. Air has been considered an incompressible liquid.

The relations between these processes are expressed by the global enthalpy balance of a room as follows (1):

$$
\begin{aligned}
V \cdot \rho_{i} \cdot c_{v} \cdot \frac{d T_{i}}{d \tau}=Q_{c} & +\sum_{I=1}^{n} h_{i_{I}} \cdot F_{I} \cdot\left(T_{S_{I}}-T_{i}\right)+ \\
& +\sum_{k=1}^{m} U_{o k_{k}} \cdot A_{o k_{k}} \cdot\left(T_{o}-T_{i}\right)+\dot{V}_{m} \cdot c_{p} \cdot\left(T_{o}-T_{i}\right)
\end{aligned}
$$


where $\dot{V}_{m}(\mathrm{~kg} / \cdot \mathrm{s})$ represents the total air mass flow rate inflowing from outdoor through a ventilation opening [14].

$$
\dot{V}_{m}=C \cdot A_{e f f} \cdot \sqrt{\left|2 \cdot g \cdot h \cdot \frac{T_{i}-T_{O}}{T_{o}} \pm 2 \Delta P_{v}\right|}
$$

The left side of equation (1) represents the change of inner energy of air in a space. The air temperature in the room of volume $\mathrm{V}$ is $\mathrm{T}_{\mathrm{i}}$. $\mathrm{T}_{\mathrm{o}}$ - outdoor temperature.

The right side of the equation (1) consists of the following terms:

- The first term Qc of the thermal equilibrium equation for a building is expressed by the sum of incoming and outgoing heat fluxes.

- The second term of the expression (1) defines heat fluxes that are being exchanged between air in a building and its internal surfaces.

- The surfaces of heat exchange are defined by $\mathrm{F}_{\mathrm{i}}$, their temperature by $T_{s_{i}}$ and convective exchange coefficient by $h_{i}$,

The convective flux that is exchanged between each internal surface of the building's envelope and the indoor air depends on the temperature of internal surfaces. The balance equation is expressed as follow:

$$
-\left.\lambda \cdot \operatorname{grad} T\right|_{s}=h_{i} \cdot\left(T_{s}-T_{i}\right)-\alpha_{e f} q_{o k s}+\alpha_{p} q_{p r}
$$

where: $\lambda$ - thermal conductivity of a surface material, $\mathrm{q}_{\mathrm{oks}}$ - density for short-wave radiation, $\alpha_{\mathrm{ef}}$ - the coefficient that defines the ratio of energy absorbed inside to the entire solar radiation energy reaching the external surface of window. $\mathrm{q}_{\mathrm{pr}}$ is the net long-wave density radiation exchange between surfaces inside the building, $\alpha_{p}$ is the thermal absorptive capacity of internal partitions.

The third term defines total conductive flux that comes or is being lost through windows of a surface $A_{o k}$ - with heat transfer coefficient denoted as $U_{o k}$. The density of the heat flux defined by Fourier equation as for a single layer wall is as follows:

$$
q_{o k}=U_{o k}\left(T_{i}-T_{o}\right)
$$

The fourth term concerns the change of enthalpy related to the air ventilation mass flow rate $\dot{\mathrm{V}}_{\mathrm{m}}(\mathrm{kg} / \mathrm{s})$. The temperature of inflowing air equals the ambient temperature. The temperature of out-flowing air equals the indoor temperature. The outdoor temperature $\mathrm{T}_{\mathrm{o}}$ is defined by the trigonometric function in chapter 5, equ.7 [4].

The wind pressure $\Delta P_{v}$ in equation (2) is defined as follows:

$$
\frac{\Delta P_{v}}{\rho_{o}}=0.5\left(C_{p 1} v_{1}^{2}-C_{p 2} v_{2}^{2}\right)
$$

where: $C_{p 1}, C_{p 2}$ are experimental pressure coefficients and $v_{1}, v_{2}$ represent the wind speed at an inlet and at an outlet, respectively.

Each direction defines a plane perpendicular to itself, on which wind velocity is projected. Then $\mathrm{v}_{1}, \mathrm{v}_{2}$ are normal wind component acting on leeward and windward building partitions, respectively. The values have been calculated via the gamma function $\Gamma$. In the presented calculations the influence of the terrain roughness on wind velocity $(\mathrm{n}=0,35)$ has been also taken into account [4]. 


\section{Methodology of numerical procedure}

The numerical model allows for the introduction of any numbers of layers, various materials of external walls, various shapes and geometry of external walls, windows, and floors of a building and any values of weather parameters. The program calculates: indoor temperatures, temperatures in any layer of the external internal walls, ventilation air rates, heat loses, and heat accumulation in walls. The heat accumulation is calculated as a difference between the heat fluxes outgoing from the interior towards a wall, and the heat fluxes towards the environment. The momentary value of the outdoor temperature is the starting value for each of the consecutive iteration. The governing equation was solved with the finite differences method for the layers of all walls and floors (possibly considering solar radiation falling on external and internal surfaces). The defined temperature values within primary layers (those in contact with the interior) allow for calculating the heat flux from the interior towards the walls. The "escape" of heat through the windows and to the ground, as well as the solar radiation heat flux inflowing through the windows, were calculated simultaneously. As a result of defining all those heat fluxes it is possible to formulate the energy balance of the interior including the enthalpy of the inflowing air flow. The "new" indoor temperature was calculated on the basis of the balance and the iterative process repeated.

The indoor air temperature in the subsequent time steps is calculated according to the following expression:

$$
T_{i}^{\prime}=T_{i}+\frac{Q_{c}-Q_{c}-Q_{w}}{\rho_{i} c_{v} V} \cdot \Delta \tau
$$

where:

$\mathrm{Q}_{1}$ - heat flux exchanged between each internal surface of a building's envelope and the air in a room,

$\mathrm{Q}_{\mathrm{w}}$ - heat flux concerning ventilation.

Walls and floors have been divided into 20 layers of thickness dependant on wall dimensions. The coupled processes of airflow and heat exchange were calculated at the initial conditions:

- the temperature inside the building and the primary temperature of the wall equals to the mean monthly outdoor temperature for particular months and wind velocity was expressed by the trigonometric function,

- the ventilation flow rates for the building had been calculated at the indoor temperature of $200^{\circ} \mathrm{C}$, and the outdoor temperature equals to the mean value.

\section{Weather parameters}

Ambient temperature as well as wind velocities with their directions data are gathered for a certain location. The identification procedure of both weather parameters has been based on 10-years of meteorological data for Warsaw. Winds are collected at $10 \mathrm{~m}$ above ground where the surface roughness equals 1 . The procedure for calculation was as follows: first wind data was grouped into eight directional sectors because the assumption was made that the full angle was sectioned into eight main directions. Every single direction defined a plane perpendicular to itself, on which wind velocity was projected, depending on the corresponding azimuths towards the south. The assumed perpendicular planes defined therefore direction of wind. Then the north ventilation intake is influenced by winds gathered between $90^{\circ}(\mathrm{E})$ and $270^{\circ}(\mathrm{W})$ through direction $(\mathrm{S})$ whereas the south ventilation opening is affected by winds collected between $90^{\circ}(\mathrm{E})$ and $270^{\circ}(\mathrm{W})$ through direction $(\mathrm{N})$. 
In thermal or air flow analyses, aforesaid planes can indicate external partitions (ventilating openings) in a building on which the wind acts at certain angles defined above, north and south [4].

The wind speeds and outdoor temperature, by the sum of a constant value and a trigonometric function, can easily be fitted. That describes the mean fluctuations throughout 24 hours. The mean values, amplitudes, and the phase shifts were obtained after a day and month averaging of the real meteorological data of ten years

$$
\langle P(t)\rangle=\bar{p}+A_{p} \sin \varpi\left(t+t_{t \varphi}\right) ; \varpi=2 \pi / \tau_{d} ; \tau_{d}=24 h
$$

$\bar{p}$ - the mean value of the weather parameter, $A_{p}-$ the amplitude, $\mathbf{t}_{\mathbf{t} \varphi}-\mathrm{a}$ phase shift, $\mathbf{t}$ - time (hr- from six o'clock in the morning).

Wind speeds were calculated with the reference to their directions.

The outdoor temperature and wind speed are defined at constant levels for certain months, defined using the mean value and a trigonometric function. The values of the parameters for July are as follows: mean value for the temperature $-(17.24)^{\circ} \mathrm{C}$, amplitude $(4.04)^{\circ} \mathrm{C}$, phase shift $-(8.23) \mathrm{hr}$. As regards wind when the northern inlet ventilating opening collects assisting winds, the mean value is $-(2.298) \mathrm{m} / \mathrm{s}$, amplitude $-(0.551) \mathrm{m} / \mathrm{s}$, phase shift $-(-9.5) \mathrm{hr}$, whereas for the southern wind: mean value is $(1.759) \mathrm{m} / \mathrm{s}$, amplitude $(0.417) \mathrm{m} / \mathrm{s}$, phase shift $(-7) \mathrm{hr}$. It is assumed that the direct solar radiation is proportionally attenuated according to the cosines of the zenith angle. The horizontal roof is influenced by total solar radiation. The solar energy gains of a required orientation have been calculated with a 15 -minute resolution. The daily sum of total solar radiation at the ground level in July in Central Europe is $17,009 \mathrm{~kJ} / \mathrm{m}^{2}$ while the monthly sum is $527,267 \mathrm{~kJ} / \mathrm{m}^{2}$ [16]. The coefficient of ground reflectivity in calculation was assumed to be 0.2

\section{Results of numerical computations - data for the regression model}

To construct the regression model, a computer simulation of the aforesaid processes had to be carried out for every insulation layer, with the window surface to wall surface ratio (wwr) changing from $5 \%$ to $50 \%$. Having computed daily time history of indoor temperatures, their maximum and minimum values for all tested cases were gathered. Using the temperature data, a regression model was then built to separately estimate the minimum and maximum indoor temperature values. The lowest and the highest indoor temperatures can also be estimated according to the wind influence as follows: assisting, opposing and no wind influence.

Two aspects are involved when indoor temperature is computed. The first is the effect of wind on intensity of air flow through the building and, in consequence, on the level of indoor temperature. Three forms of wind is available - assisting and opposing wind and no wind occurrence. Each of the wind influences the air flow differently. The second is related to solar energy transferred through opaque and transparent elements into the building and accumulated in a partition. The inside temperature must rise in this case. But on the other hand the buoyancy flux is raising as well. It means that air flow is more intensive and causes temperature drop. But of course solar radiation transferred into a building effects temperature value more then air density reduction.

As for the solar energy, the energy flow through the windows has a significant impact on the indoor temperature. Increasing insulation thickness has slight effect on the value of inside temperatures. The only case where this is not true, is the case of an uninsulated wall. In this situation, the intensity of heat exchange is substantial, because thermal resistance is the lowest among the tested cases. This effect is achieved when heating load is calculated 
for the purpose of an energy audit. The biggest difference in heating loads is observed between a non-insulated wall and a wall with the thinnest layer of insulation. Applying further layers of insulating material does not make such substantial differences in heat losses, and temperature does not change much anymore. At the smallest wwr value of 0.05 , the temperature in the building insulated with $30 \mathrm{~cm}$ of material is the lowest among all considered insulation layer cases. The building solar energy gains through the window and heat losses through opaque elements are also low. However, the heat losses are of small importance even in comparison with weak solar gains. At the wwr of 0.5 the temperature reaches the highest level because of substantial solar gains. Studying table 1, one can

Table 1. Minimum and maximum temperature values at the thickness insulation from $3 \mathrm{~cm}$ to $30 \mathrm{~cm}$ and different values of wwr parameter for three types of wind.

\begin{tabular}{|c|c|c|c|c|c|c|}
\hline \multicolumn{7}{|c|}{ Thickness insulation layer $3 \mathrm{~cm}-30 \mathrm{~cm}$} \\
\hline & \multicolumn{3}{|c|}{ Assisting wind } & \multicolumn{3}{|c|}{ Opposing wind } \\
\hline & \multicolumn{6}{|c|}{ Minimum indoor temperature } \\
\hline wwr* & East & South & West & East & South & West \\
\hline 0.05 & $25.2-24.3$ & $25.2-24.4$ & 25.124 .3 & $26.5-26.3$ & $26.5-26.3$ & $26.4-26.2$ \\
\hline 0.10 & $25.3-24.7$ & $25.3-24.7$ & $25.3-24.7$ & 26.6 & 26.6 & 26.6 \\
\hline 0.15 & $25.5-25.0$ & $25.5-25.0$ & $25.5-25.1$ & $26.8-26.9$ & $26.8-26.9$ & $26.8-27.0$ \\
\hline 0.35 & 26.0 & 26.0 & 26.2 & $27.3-27.8$ & $27.4-27.9$ & $27.6-28.3$ \\
\hline 0.50 & $26.3-26.5$ & $26.4-26.7$ & $26.7-27.1$ & $27.6-28.4$ & $27.7-28.6$ & $28.0-29.0$ \\
\hline \multicolumn{7}{|c|}{ No insulation } \\
\hline 0.05 & 21.5 & 21.5 & 21.4 & 22.1 & 22.1 & 22.1 \\
\hline 0.10 & 21.6 & 21.6 & 21.6 & 22.3 & 22.3 & 22.3 \\
\hline 0.15 & 21.7 & 21.7 & 21.7 & 22.4 & 22.4 & 22.5 \\
\hline 0.35 & 22.2 & 22.3 & 22.4 & 23.0 & 23.1 & 23.2 \\
\hline 0.50 & 22.5 & 22.6 & 22.9 & 23.4 & 23.5 & 23.7 \\
\hline \multicolumn{7}{|c|}{ Maximum indoor temperature } \\
\hline 0.05 & $27.3-26.8$ & $27.2-26.7$ & $27.1-26.6$ & $28.8-29.0$ & $28.7-28.9$ & $28.6-28.7$ \\
\hline 0.10 & $27.7-27.4$ & $27.7-27.4$ & $27.7-28.1$ & $29.2-29.5$ & $29.2-29.5$ & $29.2-29.5$ \\
\hline 0.15 & 28.0 & 28.0 & 28.2 & $29.6-30.1$ & $29.7-30.1$ & $29.8-30.3$ \\
\hline 0.35 & 28.9 & 29.2 & 29.5 & $30.4-31.1$ & $30.8-31.5$ & $31.0-31.8$ \\
\hline 0.50 & $30.6-31.2$ & $31.7-32.4$ & $32.4-33.1$ & $32.3-33.3$ & $33.4-34.5$ & $34.1-35.3$ \\
\hline \multicolumn{7}{|c|}{ No insulation } \\
\hline 0.05 & 23.3 & 23.2 & 23.1 & 23.9 & 24.9 & 23.6 \\
\hline 0.10 & 23.7 & 23.7 & 23.7 & 24.3 & 24.3 & 24.3 \\
\hline 0.15 & 24.0 & 24.1 & 24.2 & 24.7 & 24.8 & 25.0 \\
\hline 0.35 & 24.7 & 25.1 & 25.4 & 26.5 & 26.0 & 24.4 \\
\hline \multirow[t]{3}{*}{0.50} & 26.6 & 27.7 & 28.5 & 27.6 & 28.7 & 29.6 \\
\hline & \multicolumn{6}{|c|}{ No wind } \\
\hline & \multicolumn{3}{|c|}{ Minimum indoor temperature } & \multicolumn{3}{|c|}{ Maximum indoor temperature } \\
\hline 0.05 & $25.9-25.4$ & $25.9-25.4$ & $25.8-25.3$ & $28.1-27.9$ & $28.0-27.8$ & $27.9-27.7$ \\
\hline 0.10 & $26.0-25.7$ & $26.0-25.7$ & $26.0-25.7$ & $28.5-28.5$ & 28.5 & 28.5 \\
\hline 0.15 & $26.2-26.0$ & $26.2-26.0$ & $26.2-26.1$ & $28.9-29.0$ & $29.0-29.2$ & $29.1-29.3$ \\
\hline 0.35 & $26.7-27.0$ & $26.8-27.1$ & $27.0-27.4$ & $29.7-30.1$ & $30.0-30.5$ & $30.3-30.8$ \\
\hline 0.50 & $27.0-27.6$ & $27.2-27.8$ & $27.5-28.2$ & $31.5-32.4$ & 33.4 & $33.3-34.3$ \\
\hline \multicolumn{7}{|c|}{ No insulation } \\
\hline 0.05 & 21.8 & 21.8 & 21.8 & 23.7 & 23.6 & 23.4 \\
\hline 0.10 & 22.0 & 22.0 & 22.0 & 24.0 & 24.0 & 24.0 \\
\hline 0.15 & 22.1 & 22.1 & 22.2 & 24.4 & 24.5 & 24.7 \\
\hline 0.35 & 22.6 & 22.7 & 22.8 & 25.2 & 25.5 & 25.9 \\
\hline 0.50 & 23.0 & 23.1 & 23.3 & 27.1 & 28.3 & 29.0 \\
\hline
\end{tabular}

*) - window area to a wall surface ratio 
realize, that at the certain surface of window the difference in temperatures values is no longer observed, no matter how thick the insulation is. For instance, the value of minimum temperature is $26^{\circ} \mathrm{C}$ when wwr is 0.35 and assisting wind is present. The same situation can be observed at the opposing wind when wwr parameter is 0.1 . The indoor temperature reaches $26.6^{\circ} \mathrm{C}$.

The highest temperature of $32.2^{\circ} \mathrm{C}$ occurs at the eastern window at 2.27 p.m. $(14,27)$ when wwr equals to 0.5 .

The lowest value $28^{\circ} \mathrm{C}$ occurs at 3.15 p.m., $(15,15)$ at wwr of 0.05 . But $28^{\circ} \mathrm{C}$ is the highest value observed for the wwr of 0.05 . When assisting and opposing wind is taken into account, the hours with maximum temperatures are practically unchanged, although the temperature values are different. As it was said above, indoor temperatures are the effect of, among others, intensity of ventilation. The ventilation flow fluctuates due to variable values of buoyancy force and wind pressure. Absence of wind may create a reversed flow [3]. It happens usually during hot hours, and creates more uncomfortable thermal conditions. In the absence of wind the air flow is driven by buoyancy forces only.

\section{The regression model}

Fig. 1 shows the computed indoor temperatures. They are plotted against values of wwr parameter. Fig. 1a displays the linear approximation to the estimated minimum indoor temperatures while fig. $1 \mathrm{~b}$ - the maximum ones. Both graphs were plotted for a situation when assisting wind affects air exchange in the building for a different surface of western window glazing. The eastern and southern windows are assumed to stay unchanged at wwr of 0.1 .

The regression model created for indoor temperature concerns a building which the envelope is insulated with a layer thickness within a range from 3 to $30 \mathrm{~cm}$ thick. The equation is written below.

$$
T_{\min / \max }=a \cdot x+b
$$

where: variable $x$ assumes the value of wwr parameter, $a$ and $b$ are the constants for the linear approximation. Their values for all tested cases are put in table 2. The constants values must be different for minimum and maximum temperature approximation, as well as for each of three geographical windows orientation: E. S and W.
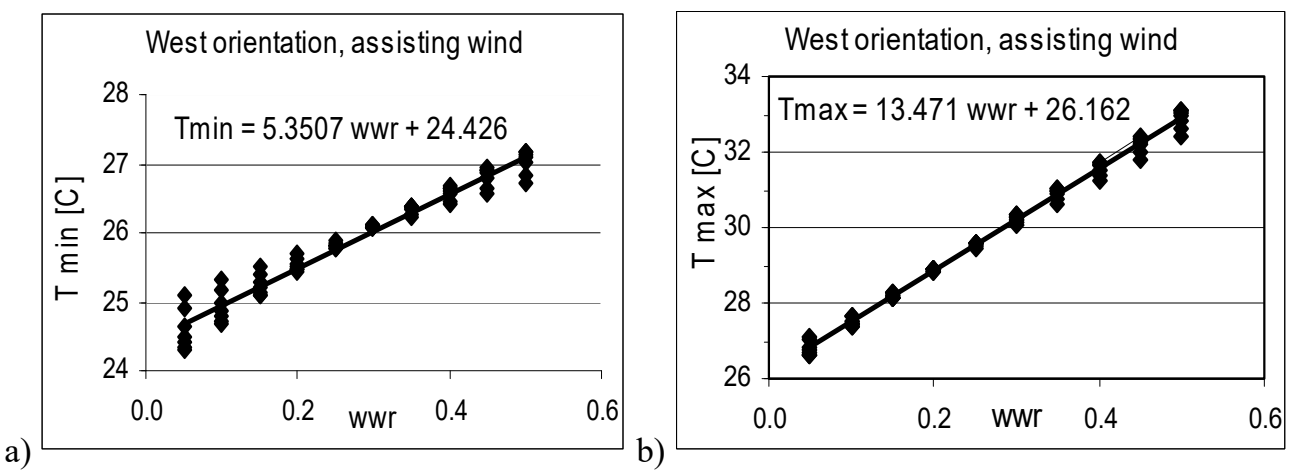

Fig. 1. Regression function to estimate a) Tmin b) Tmax, in the space during summer time at the assisting wind, window of western orientation. 
The values depend on the influence of wind too: they are different for the situation when the wind increases air exchange processor, when it reduces it and when does not impact the flow.

Table 2. Constants' value $a$ and $b$ for the proposed regression model.

\begin{tabular}{|c|c|c|c|c|c|c|}
\hline \multirow{2}{*}{$\begin{array}{c}\text { Window's } \\
\text { orientation }\end{array}$} & \multicolumn{2}{|c|}{ Assisting wind } & \multicolumn{2}{c|}{ Opposing wind } & \multicolumn{2}{c|}{ No wind } \\
\cline { 2 - 7 } & \multicolumn{2}{|c|}{ Tmin } & \multicolumn{2}{c|}{ Tmin } & \multicolumn{2}{c|}{ Tmin } \\
\cline { 2 - 7 } & $\mathrm{a}$ & $\mathrm{b}$ & $\mathrm{a}$ & $\mathrm{b}$ & $\mathrm{a}$ & $\mathrm{b}$ \\
\hline $\mathrm{E}$ & 3.9113 & 24.565 & 3.7851 & 26.258 & 3.9460 & 25.475 \\
\hline $\mathrm{S}$ & 4.3435 & 24.523 & 4.2432 & 26.214 & 4.4021 & 25.431 \\
\hline $\mathrm{W}$ & 5.3507 & 24.426 & 5.2848 & 26.114 & 5.4388 & 25.331 \\
\hline \multicolumn{3}{|c|}{ Tmaxyyyyyy} & \multicolumn{2}{c|}{ Tmax } & \multicolumn{3}{c|}{ Tmax } \\
\hline $\mathrm{E}$ & 8.8691 & 26.627 & 8.8804 & 28.566 & 9.0177 & 27.623 \\
\hline $\mathrm{S}$ & 11.7040 & 26.338 & 11.7600 & 28.272 & 11.8880 & 27.331 \\
\hline $\mathrm{W}$ & 13.4710 & 26.162 & 13.6160 & 28.089 & 13.786 & 27.143 \\
\hline
\end{tabular}

\section{Conclusion}

The regression model characterized in this paper, offers a simple solution which might help to anticipate high indoor temperatures during hot summertime. While it does not provide any recommendations on a valid course of action when heat events occurs, it does provide the knowledge about the phenomena at the stage of preliminary design. The information obtained using the regression model provides an opportunity to reduce or even omit the overheating phenomena. The knowledge of values of indoor temperature guides what sort of interventions can be chosen.

The model estimates minimum and maximum indoor temperature for different window surface to wall surface ratios. The model is based on values of indoor temperatures previously computed for unsteady heat and air exchange processes for selected representative building. The model is applicable to naturally ventilated single family buildings sited at open space that are located in meteorological conditions of the temperate European climate. But when the weather parameters are quite different than those applied to the model, new data should be computed and new linear approximation needs to be obtained.

The regression model can be easily applied by architects to deliver useful information, and allows making correct decisions at the early stages of the design process. The model can find an application within a design process of single family or small houses, when the design team is rather small and cost of the project cannot be high. This simple tool gives an opportunity to investigate several alternatives, and choose the best one. The tool might stimulate architects, to get to know how big windows, or more precisely - solar radiation gained through them, can influence the minimum and maximum values of indoor temperature.

When a building is equipped with natural ventilation only, during periods of hot weather, thermal comfort can hardly be affordable. The energy-consuming devices can be solutions during these periods. Unfortunately nowadays in air-tight buildings with large windows overheating is not rare, especially when internal heat gains are high, for instance in schools. The architects of these modern buildings assume that large windows can replace sustainable sources of energy for the heating season. However, they do not pay enough attention to the heat and air exchange processes occurring during summer, which affects comfort conditions in buildings. 


\section{Appendix}

\section{Theoretical model and boundary conditions and heat conduction equation}

The transient temperature field in a wall is described by the one-dimensional conduction heat transfer equation (1A), $\mathrm{c}_{\mathrm{p}} \mathrm{J} /(\mathrm{kg} \cdot \mathrm{K})$ - specific heat, $\rho \mathrm{kg} / \mathrm{m}^{3}$ - density of each subsequent layers of material.

$$
\frac{\partial T}{\partial \tau}=\frac{\lambda}{\rho \cdot c} \cdot \frac{\partial^{2} T}{\partial x^{2}}
$$

and the unsteady boundary conditions:

- Temperature in a building is assumed to be the lump parameter. The boundary conditions of the above governing equation on the internal surface are determined as

$$
h_{i} \cdot\left[T_{s c 1}-T_{i}\right]=-\lambda_{1} \cdot\left(\frac{\partial T}{\partial x}\right)_{1}
$$

index ,1" denotes the first, from inside, layer of the wall material,

- For the multi layer partition the boundary condition at the boundary layers is as follows

$$
-\lambda_{j} \cdot\left(\frac{\partial T}{\partial x}\right)_{j}=-\lambda_{j+1} \cdot\left(\frac{\partial T}{\partial x}\right)_{j+1}
$$

On external surfaces the boundary condition takes in to account the heat flux coming from the solar radiation - chapter 3 , equ. 3 .

The fields of temperature in building partitions were calculated using the finite differences method. The temperatures ware calculated in the middle of each layer. The time step was assumed to be in accordance with von Neumanna stability criterion.

\section{Reference}

1. A. Beizaee, K. Lomas, Build. Environ. 65, 1-7 (2013)

2. C. Brunsgaard, P. Dvořáková, Pavla, A. Wyckmans, W. Stutterecker, M. Laskari, M. Almeida, K. Kabele, Z. Magyar, P. Bartkiewicz, P. Op't Veld, Build. Environ. 72, $1-14$ (2014)

3. D. Bzowska, Inst. of Fundamental Technological Research Reports, PAS (2/2007)

4. D. Bzowska, Arch. Civ. Eng. 47, 1 (2001)

5. D. Coley, T. Kershaw, Build. Environ. 45, 89-93 (2010)

6. F. Encinas, A. De Herder, Energ. Buildings 65, 55-65 (2013)

7. A. Gasparella, G. Pernigotto, F. Cappelletti, P. Romagnoni, P. Baggio, Energ. Buildings 43, 1030-1037 (2011)

8. S. Grynning, A. Gustavsen, B. Time, B. P. Jelle, Energ. Buildings 61, 185-192 (2013)

9. D. Heim et al., Optimization of double skin facade for energy performance and environmental quality, in Polish, Monogrphy, Univ. press PŁ, (2013)

10. T. Kim, M. Todorovic, Energ. Buildings 63, 108-118 (2013)

11. T. Kisilewicz, The influence of resistive, dynamic and spectral features of the building walls on the thermal balance of the low energy buildings, PK, (2008)

12. V. Leskvar., M. Premrov, Energ. Buildings 43, 3410-3418 (2011)

13. Y. Li, A. Delsante, Build. Environ. 36, 59-71 (2001) 
14. P. Linden, Annu. Rev. Fluid Mech. 31, (1999)

15. M. Persson, A. Roos, M. Wall, Energ. Buildings 38, 181-188 (2006)

16. Zb. Pluta, Theory for solar energy photo-thermal conversion, PW (2000)

17. S.M. Porritt, P.C. Cropper, L. Shao, C.I. Goodier, Energ. Buildings 55, 16-27 (2012)

18. D. Sailor, Build. Environ. 78, 81-88 (2014)

19. R. Santos, R. Martins, H. Gervásio, L. Simões da Silva, Energ. Buildings 79, $58-73$ (2014) 